BRAZILLAN JOURNAL

www.bjournal.com.br
ISSN 0100-879X

Volume 44 (8) 729-813 August 2011

BIOMEDICAL SCIENCES

AND

CLINICAL INVESTIGATION

Braz J Med Biol Res, August 2011, Volume 44(8) 786-792

doi: 10.1590/S0100-879X2011007500099

Effect of tamoxifen on the coronary vascular reactivity of spontaneously hypertensive female rats

M.V. Borgo, A.B. Lopes, S.A. Gouvêa, W.G. Romero, M.R. Moyses, N.S. Bissoli and G.R. Abreu

The Brazilian Journal of Medical and Biological Research is partially financed by
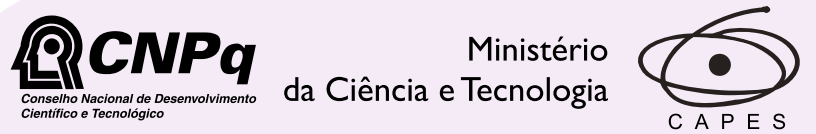

Ministério da Educação
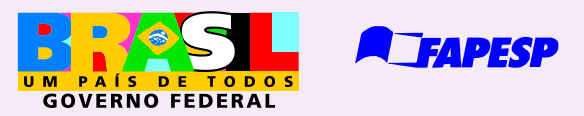

Institutional Sponsors
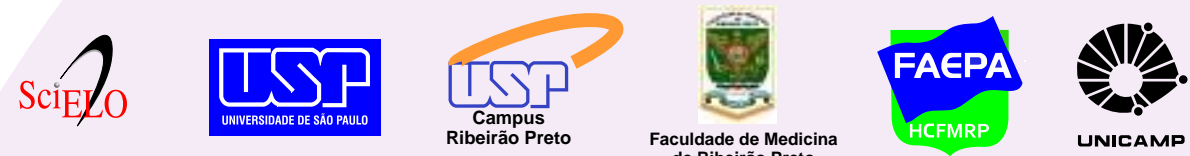

UNICAMP
Ф SHIMADZU

Explore High - Performance MS Orbitrap Technology In Proteomics \& Metabolomics

$\underset{\text { analitica }}{\text { analiticaweb.com.br }}$ SCIENTIFIC 


\title{
Effect of tamoxifen on the coronary vascular reactivity of spontaneously hypertensive female rats
}

\author{
M.V. Borgo, A.B. Lopes, S.A. Gouvêa, W.G. Romero, M.R. Moyses, \\ N.S. Bissoli and G.R. Abreu \\ Departamento de Ciências Fisiológicas, Centro Biomédico, \\ Universidade Federal do Espírito Santo, Vitória, ES, Brasil
}

\begin{abstract}
Tamoxifen has been associated with a reduction in the incidence of myocardial infarction. However, the effects of tamoxifen on coronary reactivity have not been fully elucidated. The objective of this study was to determine the effects of chronic treatment with tamoxifen on coronary vascular reactivity in spontaneously hypertensive rats (SHR). Female SHR were divided into four groups ( $\mathrm{N}=7$ each): sham-operated (SHAM), sham-operated and treated with tamoxifen $(0.1 \mathrm{mg} / 100 \mathrm{~g})$ by gavage for 90 days (TAMOX), ovariectomized (OVX), and ovariectomized and treated with tamoxifen (OVX+TAMOX). Mean arterial pressure (MAP), heart rate (HR), coronary perfusion pressure (CPP), and coronary vascular reactivity were measured. MAP and HR were reduced (9.42 and $11.67 \%$, respectively) in the OVX+TAMOX group compared to the OVX group (P<0.01). The coronary vascular reactivity of the OVX+TAMOX group presented smaller vasoconstrictor responses to acetylcholine $(2-64 \mu \mathrm{g})$ when compared to the OVX group $(P<0.01)$ and this response was similar to that of the SHAM group. The adenosine-induced vasodilator response was greater in the TAMOX group compared to the SHAM and OVX groups (P < 0.05). Baseline CPP was higher in OVX+TAMOX and TAMOX groups (136 \pm 3.6 and $130 \pm 1.5 \mathrm{mmHg}$ ) than in OVX and SHAM groups (96 \pm 2 and 119 $\pm 2.3 \mathrm{mmHg} ; \mathrm{P}<0.01$ ). Tamoxifen, when combined with OVX, attenuated the vasoconstriction induced by acetylcholine and increased the adenosine-induced vasodilatory response, as well as reducing the MAP, suggesting beneficial effects of tamoxifen therapy on coronary vascular reactivity after menopause.
\end{abstract}

Key words: Tamoxifen; Estrogen; Hypertension; Menopause; Coronary

\section{Introduction}

The incidence of coronary heart disease (CHD) is significantly lower in women than in men (1) and increases in women after natural or surgically induced menopause (2). Postmenopausal estrogen replacement therapy is a protective factor against the development of CHD (3). However, two randomized prospective prevention trials, the Women's Health Initiative (WHI) (4) and the Heart and Estrogen/Progestin Replacement Study (HERS I and II) (5), showed that hormone replacement therapy (HRT) with estrogen and progesterone may actually increase the risk of cardiovascular disease in postmenopausal women. The reasons for this paradoxical characterization of HRT as both beneficial and detrimental are not clear. Estrogen also affects vascular tone by promoting vasodilatory effects through other pathways (6) such as the stimulation of endothelial nitric oxide synthase (eNOS) (7), the increase of calcium efflux from vascular smooth muscle cells, the activation of guanylate cyclase, inhibition of ATP-sensitive $\mathrm{K}^{+}$channels (KATP), inhibition of $\mathrm{Ca}^{2+}$-activated potassium channels $\left(\mathrm{K}_{\mathrm{Ca}}\right)(8)$, and inhibition of proliferation of vascular smooth muscle cells (VSMC) (9).

In humans with coronary heart disease, there is abnormal coronary vasoconstriction in response to acetylcholine due to endothelial dysfunction (10). Thus, the effects of estrogen on both endothelial and vascular smooth muscle cells (11) lead to vasodilatation of various vascular beds, including the coronary vascular bed (12).

Increased interest is emerging in the evaluation of selective estrogen-receptor (ER) modulators (SERM), agents with estrogen-like effects on bone and on cardiovascular

Correspondence: S.A. Gouvêa, Departamento de Ciências Fisiológicas, Centro de Ciências da Saúde, UFES, Av. Marechal Campos, 1468, 29042-755 Vitória, ES, Brasil. Fax: +55-27-3335-7330. E-mail: sagouvea@ppgcf.ufes.br

Received October 25, 2010. Accepted July 13, 2011. Available online August 12, 2011. Published August 19, 2011. 
risk factors but without proliferative effects on breast tissue. Tamoxifen is a SERM with mixed estrogen agonist and antagonist properties that is currently used for the treatment of breast cancer, which exhibits higher efficacy against ER-positive tumors (13).

The proposed mechanisms by which tamoxifen could alter vascular reactivity, including antagonism of several ion channels and calmodulin, and inhibition of myosin light chain kinase, are consistent with studies speculating that several potentially important tamoxifen actions are ER-independent (14). Clinical observations have shown that treatment with tamoxifen reduces the incidence of ischemic heart disease and coronary atherosclerosis (15). Other studies have also reported decreases in total serum cholesterol and HDL cholesterol with tamoxifen treatment (16). Additionally, in experimental studies, tamoxifen exerted effects similar to those of estrogen on vascular relaxation due to several mechanisms, including antagonism of various ion channels (17).

In the spontaneously hypertensive rat (SHR) model, the development of hypertension is associated with an increase in total peripheral resistance, a reduction in stroke volume (18), as well as the development of progressive cardiac hypertrophy. In SHR, functional vascular alterations precede the development of arterial hypertension, with reduction of distensibility and vascular compliance resulting from wall media hypertrophy (19).

In light of this, it becomes necessary to clarify the effect of tamoxifen on coronary reactivity under hypertensive conditions in SHR in order to identify the mechanisms involved in SERM-induced cardiovascular effects, especially those on the coronary circulation of the postmenopausal period. Thus, the objective of the present study was to determine the effects of chronic treatment with tamoxifen on coronary vascular reactivity in SHR.

\section{Material and Methods}

Experiments were performed on female SHR (80 to $100 \mathrm{~g}$ ) obtained from the Departamento de Ciências Fisiológicas, Universidade Federal do Espírito Santo (UFES), Brazil. The project was approved by the Institutional Ethics Committee for animal research (Ethics Committee for the Use of Animals, UFES, protocol\#014/2010), and all experiments were conducted in accordance with the Guide for the Care and Use of Laboratory Animals published by the US National Institutes of Health (NIH Publication \#85-23, revised 1996).

Female rats from our breeding stock were randomly divided into four groups ( $\mathrm{N}=7$ per group): sham-operated (SHAM), sham-operated and tamoxifen-treated (TAMOX), ovariectomized (OVX), and ovariectomized and tamoxifentreated (OVX+TAMOX).

All animals were maintained in a room with controlled temperature $\left(23-25^{\circ} \mathrm{C}\right)$ and light-dark cycle (lights on from 6:00 am to 6:00 pm). Water was provided ad libitum. Cages were always cleaned in the morning (6:00 to 12:00 am), and all animals were handled identically during their growth period.

\section{Surgical procedures}

Ovariectomy was performed under general anesthesia with chloral hydrate, $40 \mathrm{mg} / \mathrm{kg}$, ip. Briefly, a peritoneal incision was made to expose the uterine tube, and the ovaries were removed bilaterally. Then, the abdominal wall was surgically closed, and animals were given 1 week to recover. During surgery, animals received an appropriate dose of antibiotic (2.5\% enrofloxacin, $0.1 \mathrm{~mL}$ per rat, im).

\section{Tamoxifen treatment}

The tamoxifen-treated animals received a daily dose of tamoxifen $(0.1 \mathrm{mg} / 100 \mathrm{~g}$ body weight) for 90 days; rats were gently restrained and received tamoxifen citrate saline (Sigma-Aldrich, USA) dissolved in water $(1 \mathrm{~mL})$ via oral gavage. The SHAM and OVX groups received vehicle only (i.e., water) via oral gavage.

At the end of the 90-day experimental protocol, rats were anesthetized with ketamine and xylazine (50 and 10 $\mathrm{mg} / \mathrm{kg}, i p)$. For the direct measurement of mean arterial pressure (MAP) and heart rate (HR), a polyethylene (PE50 ) catheter (attached to PE-10 tubing) was inserted into the femoral artery and tunneled to the dorsal neck region. The animals remained in a fasted state until 7:00 to 8:00 am of the next day to obtain direct measurements of blood pressure in awake and unrestrained animals (TRA021 BP transducer coupled to an ML 110 Amplifier; AD Instruments, Australia). Blood pressure and HR values were calculated for each animal from continuous recordings averaged over a 30-min period (Chart 5.5.1; AD Instruments).

\section{Langendorff preparation}

Experiments were performed on isolated perfused hearts from female SHR. The rats were anesthetized with chloral hydrate $(40 \mathrm{mg} / \mathrm{kg}$, ip) and injected with heparin $(100 \mathrm{U} / \mathrm{kg}, \mathrm{sc})$. Fifteen minutes after heparin injection, the rats were killed, and their hearts were immediately excised and perfused at a constant flow. Studies on the coronary vascular bed were performed on whole hearts using a Langendorff preparation for perfused isolated hearts (20). Briefly, using a Langendorff apparatus (Hugo Sachs Electronics, Germany), the isolated hearts were perfused with modified Krebs solution containing $120 \mathrm{mM} \mathrm{NaCl}, 1.26 \mathrm{mM}$ $\mathrm{CaCl}_{2} \cdot 2 \mathrm{H}_{2} \mathrm{O}, 5.4 \mathrm{mM} \mathrm{KCl}, 2.5 \mathrm{mM} \mathrm{MgSO} 4 \cdot 7 \mathrm{H}_{2} \mathrm{O}, 2 \mathrm{mM}$ $\mathrm{NaH}_{2} \mathrm{PO}_{4} \cdot \mathrm{H}_{2} \mathrm{O}, 27 \mathrm{mM} \mathrm{NaHCO}_{3}, 1.2 \mathrm{mM} \mathrm{Na}_{2} \mathrm{SO}_{4}, 30 \mu \mathrm{M}$ EDTA, and $11.0 \mathrm{mM}$ glucose. The solution was equilibrated with a $95 \%$ oxygen and $5 \%$ carbon dioxide at a controlled pressure of $100 \mathrm{mmHg}$ to give a $\mathrm{pH}$ of 7.4 . Langendorff preparations were perfused at a rate of $10 \mathrm{~mL} / \mathrm{min}$ with a peristaltic pump (MS-Reglo 4 channels; Hugo Sachs Electronics) and maintained at a temperature of $37^{\circ} \mathrm{C}$. A 
fluid-filled balloon secured to a stainless steel cannula was introduced into the left ventricle and connected to a TPS-2 Statham transducer (Incor, Brazil) to measure the isovolumetric cardiac force. The balloon was inflated with a spindle syringe until it produced a preload of $10 \mathrm{mmHg}$.

Coronary perfusion pressure (CPP) was monitored using a TPS-2 Statham transducer connected to a sidearm of the aortic perfusion catheter. Once the preparation was stabilized, baseline CPP was measured after about $40 \mathrm{~min}$. Concentration-response curves to adenosine (Sigma, USA) were constructed on the basis of a series of bolus injections ( 2 to $64 \mu \mathrm{g}$ in an injection volume of $0.1 \mathrm{~mL}$ saline) administered at 10-min intervals. Dose-response curves to acetylcholine (Sigma, USA) were constructed on the basis of a series of bolus injections ( 0.2 to $16 \mu \mathrm{g}$ in an injection volume of $0.1 \mathrm{~mL}$ saline) administered at 10-min intervals. The vasoconstrictor response to acetylcholine was also measured in the coronary vascular bed of SHAM $(\mathrm{N}=7)$ and $\operatorname{OVX}(\mathrm{N}=7)$ Wistar groups.

\section{Statistical analysis}

Data are reported as means \pm SEM for $N=7$ per group. Data for basal MAP, HR and CPP of the four groups were compared by repeated measures one-way analysis of variance (ANOVA). Differences between groups were determined by the Tukey post hoc test. Coronary vascular reactivity data were tested by two-way ANOVA followed by the Tukey post hoc test for multiple comparisons. Statistical significance was set at $\mathrm{P}<0.05$.

\section{Results}

Table 1 summarizes the resting MAP values obtained from conscious animals 90 days after the beginning of treatment. As expected, MAP was significantly higher in OVX rats $(191 \pm 3 \mathrm{mmHg})$ than in SHAM rats $(168 \pm 3$ $\mathrm{mmHg}, \mathrm{P}<0.01)$. Administration of tamoxifen for 90 days decreased but did not normalize MAP $(173 \pm 1 \mathrm{mmHg})$ in the OVX+TAMOX group. MAP $(161.5 \pm 2 \mathrm{mmHg})$ was not decreased in SHR treated with tamoxifen compared to the SHAM group. Baseline HR values did not differ significantly among the following groups of female SHR: SHAM (427 \pm $9 \mathrm{bpm})$, TAMOX (414 $\pm 7 \mathrm{bpm})$ and OVX (437 $\pm 9 \mathrm{bpm})$. OVX+TAMOX rats exhibited a significant decrease in HR (386 $\pm 7 \mathrm{bpm})$ compared to the SHAM and OVX groups ( $P$ $<0.05$ and $P<0.01$, respectively).

Data for baseline CPP in each treatment group are shown in Figure 1. Baseline CPP was significantly higher in OVX+TAMOX $(136 \pm 3.6 \mathrm{mmHg})$ than in SHAM $(119 \pm$ $2 \mathrm{mmHg}$ ) rats. In OVX rats, castration caused a significant reduction $(\mathrm{P}<0.05)$ in baseline CPP $(98 \pm 1.8 \mathrm{mmHg})$ relative to that of SHAM rats. The treatment of non-castrated female rats with tamoxifen for 90 days resulted in a significantly greater baseline CPP $(130 \pm 1.5 \mathrm{mmHg})$ than that of SHAM rats $(119 \pm 2 \mathrm{mmHg} ; \mathrm{P}<0.05)$.
Table 1. Baseline values of blood pressure obtained from spontaneously hypertensive female rats in the four treatment groups.

\begin{tabular}{lcccc}
\hline Parameter & SHAM & TAMOX & OVX & OVX+TAMOX \\
\hline MAP $(\mathrm{mmHg})$ & $168 \pm 3$ & $161.5 \pm 2$ & $191 \pm 3^{*+}$ & $173 \pm 1^{\#}$ \\
\hline
\end{tabular}

Data are reported as means \pm SEM $(\mathrm{N}=7$ animals in each group). SHAM = sham-operated; OVX = ovariectomized; TAMOX $=$ tamoxifen-treated $(0.1 \mathrm{mg} / 100 \mathrm{~g}$ body weight $)$ for 90 days; OVX+TAMOX = ovariectomized + treated with tamoxifen. ${ }^{*} \mathrm{P}<0.01$ compared to the respective SHAM group; ${ }^{*} \mathrm{P}<0.01$ compared to the OVX group; ${ }^{+} \mathrm{P}<0.01$ compared to the TAMOX group (ANOVA followed by the Tukey post hoc test).

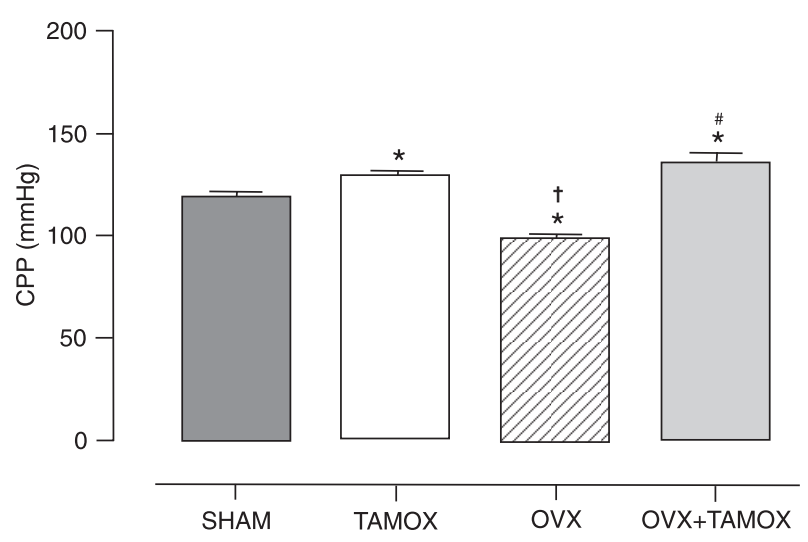

Figure 1. Coronary perfusion pressure (CPP) of isolated hearts obtained from spontaneously hypertensive female rats in the four treatment groups (SHAM, TAMOX, OVX, and OVX+TAMOX; for abbreviations, see legend to Table 1). Data are reported as means \pm SEM $\left(N=7\right.$ animals in each group). ${ }^{*} P<0.05$ compared to the SHAM group; \#P < 0.01 compared to the OVX group; ${ }^{\dagger} \mathrm{P}$ $<0.01$ compared to the TAMOX group (ANOVA followed by the Tukey post hoc test).

As shown in Figure 2, CPP values are reported as a percentage of coronary bed contraction with increasing log doses of acetylcholine $(0.5,1,2,4,8,16$, and $64 \mu \mathrm{g} / \mathrm{mL})$ in SHAM, TAMOX, OVX, and OVX+TAMOX groups. There were no differences in acetylcholine-induced constriction among SHAM $(0.35 \pm 0.2,1.2 \pm 0.3$, and $2.96 \pm 0.4 \%)$, $\operatorname{TAMOX}(0.3 \pm 0.14,1.7 \pm 0.4$, and $5.5 \pm 0.3 \%)$, OVX $(0.87$ $\pm 0.25,1.8 \pm 0.47$, and $5.45 \pm 0.86 \%$ ) and OVX+TAMOX $(0.39 \pm 0.2,0.63 \pm 0.2$, and $1.9 \pm 0.4 \%)$ groups at doses of $0.2,0.5$, and $1 \mu \mathrm{g}$, respectively.

There were statistically significant reductions in acetylcholine-induced constriction at doses of $2,4,8$, and $16 \mu \mathrm{g}(\mathrm{P}<0.01)$ in the SHAM $(4.8 \pm 0.5,6.8 \pm 0.5,9.8 \pm$ 0.16 , and $12.5 \pm 1 \%$, respectively) and OVX+TAMOX (4.7 $\pm 0.7,6.6 \pm 0.96,8.6 \pm 1.4$, and $11.1 \pm 1.9 \%$, respectively) groups compared to the TAMOX $(11.5 \pm 0.9,15.8 \pm 0.75$, $19.8 \pm 0.3$, and $27.3 \pm 0.75 \%$, respectively), and OVX (10.6 
$\pm 1.2,15.9 \pm 1.7,23.6 \pm 2.2$, and $26.9 \pm 3.2 \%$, respectively) groups, as shown in Figure 2.

The usual vasoconstrictor response of the Wistar SHAM and OVX groups was similar to that of the SHR SHAM and OVX groups. Acetylcholine promoted a greater vasoconstrictor response in the Wistar OVX group when compared to Wistar groups at all doses used $(7 \pm 1,18 \pm 2,29 \pm 2,42$ $\pm 2,51 \pm 3,51 \pm 3,53 \pm 3 \%$ and $0 \pm 1,6 \pm 1,11 \pm 1,19 \pm$ $2,30 \pm 2,31 \pm 3,33 \pm 3 \%$, respectively; $\mathrm{P}<0.05$ ).

The effects of tamoxifen treatment for 90 days are shown in Figure 3. CPP values are reported as a percentage of coronary bed dilation with increasing concentrations of adenosine. There were no differences in adenosine-induced dilatation among the SHAM $(-1.1 \pm 0.4$ and $-2.1 \pm 0.4 \%)$, TAMOX (-1.7 \pm 0.5 and $-2.9 \pm 0.5 \%)$, OVX $(-0.7 \pm 0.4$ and $-1.5 \pm 0.5 \%)$, and OVX+TAMOX (-1.0 \pm 0.4 and $-3.9 \pm 0.9 \%)$ groups at doses of either 2 or $4 \mu \mathrm{g}$.

At adenosine doses of $8,16,32$, and $64 \mu \mathrm{g}$, the TAMOX group $(-6.9 \pm 0.5,-8.9 \pm 0.8,-16.3 \pm 1.1$, and $-20.9 \pm 0.6 \%$, respectively) and OVX+TAMOX group (-5.9 $\pm 0.6,-9.5 \pm$ $0.8,-11.0 \pm 1.6$, and $-18.2 \pm 3.8 \%$, respectively) showed a significant dose-dependent increase in the vasodilatory response compared to the SHAM group $(-3.2 \pm 0.5,-5.7$ $\pm 1.3,-7.9 \pm 1.0$, and $-12.8 \pm 1 \%$, respectively) and OVX group $(-2.9 \pm 0.6,-5.6 \pm 0.9,-6.4 \pm 0.6$, and $-8.5 \pm 0.6 \%$, respectively).

\section{Discussion}

SERMs are compounds that exert estrogen-like effects on some target tissues but antagonize the effects of estrogens in others. Tamoxifen is widely used as adjuvant therapy in the treatment of breast cancer (13). This class of drugs has already been shown to promote vascular relaxation by acting on VSMC and endothelial cells (21). However, the effects of these drugs on the cardiovascular system have been the subject of many studies, as this drug class mimics or antagonizes the cardiovascular effects of estrogen mediated by estrogen receptors. Blood pressure elevation after menopause is considered to be the most important cardiovascular risk factor (22).

The present study shows a significant reduction in blood pressure in response to tamoxifen, although it was not sufficient to restore the blood pressure of SHR to normotensive levels. However, the same treatment attenuated the blood pressure increase induced after ovariectomy (23).

The blood pressure attenuation observed in the OVX+TAMOX group may be related to the vascular effects of tamoxifen, such as inhibition of voltage-dependent calcium channels in VSMC and stimulation of vascular endothelium promoting the relaxation of coronary artery rings (22). Morphological changes in the vascular bed were also observed. A clinical study showed a significant reduction in the intimamedia arterial thickness in postmenopausal women after treatment with tamoxifen for 1 year (24). No differences in
MAP were observed in TAMOX and OVX+TAMOX groups when compared to the SHAM group.

There was a significant reduction of $\mathrm{HR}$ in the

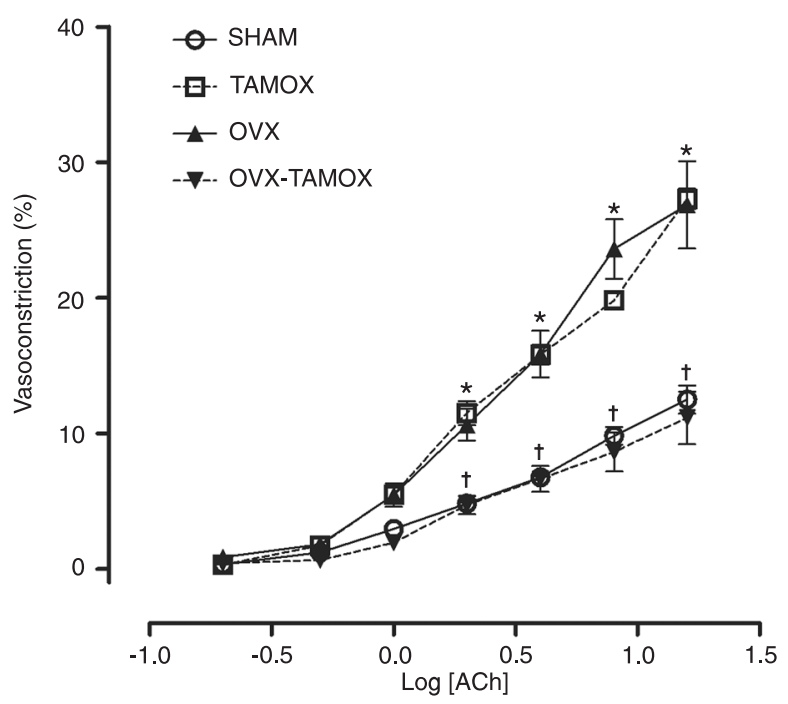

Figure 2. Coronary perfusion pressure values reported as a percentage of coronary vascular bed contraction with increasing doses of acetylcholine (Ach) in the four treatment groups (SHAM, TAMOX, OVX, and OVX+TAMOX; for abbreviations, see legend to Table 1). Data are reported as means \pm SEM $(\mathrm{N}=7$ rats in each group). ${ }^{*} \mathrm{P}<0.01$ compared to the SHAM group; ${ }^{\dagger} \mathrm{P}<0.01$ compared to the OVX group (ANOVA followed by the Tukey post hoc test).

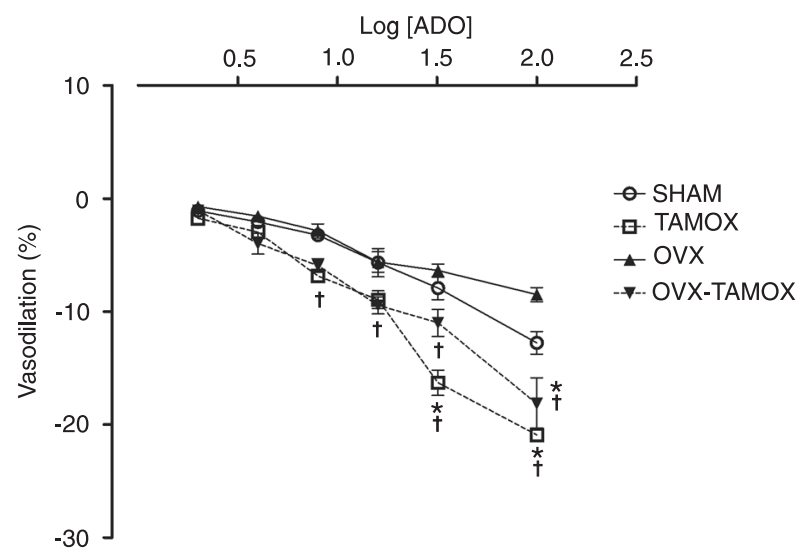

Figure 3. Coronary perfusion pressure values reported as a percentage of coronary vascular bed dilatation with increasing concentrations of adenosine (ADO) in the four treatment groups (SHAM, TAMOX, OVX, and OVX+TAMOX; for abbreviations, see legend to Table 1). Data are reported as means \pm SEM $(N=7$ rats in each group). ${ }^{*} \mathrm{P}<0.05$ compared to the SHAM group; ${ }^{\dagger} \mathrm{P}<$ 0.05 compared to the OVX group (ANOVA followed by the Tukey post hoc test). 
OVX+TAMOX group when compared to SHAM and OVX groups. SHR have elevated HR (25); thus, the HR reduction after treatment with tamoxifen may be attributed to the agonist activity of estrogen in baroreceptor reflex modulation, suggesting a facilitatory role of estrogen in cholinergic neurotransmission in the central nervous system (26). Clinical studies have demonstrated that vagal absence of estrogen reduces vagal activity and increases sympathetic activity, and that both effects are reversed by estrogen replacement (27). Therefore, tamoxifen may have effects similar to those of estrogen by directly influencing autonomic function, thus mimicking the protective effect of this hormone on the cardiovascular system (28).

The experimental model used in our study had some methodological limitations, in particular, denervation and absence of peripheral humoral factors in excised organ preparations such as the Langendorff preparation. However, the isolated heart technique is highly reproducible, allowing a detailed study of the pathophysiological mechanisms involved (29).

Regarding CPP, we observed that tamoxifen treatment elevated basal pressure independently of estrogen depletion. Another finding is that the OVX group had a lower basal pressure than the other groups. Previous studies have demonstrated that castration reduces $\operatorname{CPP}(30,31)$, indicating that there are direct actions of estrogen on coronary vascular tonus, such as a cardioprotective effect. Additionally, tamoxifen therapy was able to promote a significant elevation in CPP, demonstrating that SERMs may mimic the beneficial effects of estrogen HRT.

It is known that acetylcholine can produce vasoconstriction directly by stimulating muscarinic receptors on vascular smooth muscle and indirectly through muscarinic receptors located on the vascular endothelium (32). Our data have confirmed literature findings showing that acetylcholine promotes vasoconstriction in the coronary bed of normotensive animals (20).

Our results show, a smaller vasoconstrictor response to acetylcholine in the SHR groups and a greater vasodilatory response to adenosine in the OVX+TAMOX group when compared to the OVX group, which showed an exacerbated contractile response when compared to the SHAM group. Therefore, one may conclude that coronary vascular reactivity is impaired in the absence of estrogen and that treatment with tamoxifen may improve such impairment. On the other hand, the TAMOX group showed an equally impaired contractile response when compared to the OVX group. The previously described reduction in the expression (33) and half-life of estrogen receptors (34) could have occurred in response to tamoxifen, which associates with endogenous estrogen, attenuating the vasodilatory response observed in the TAMOX+OVX group and exacerbating the coronary vasoconstrictor response in the TAMOX group to the extent observed in the OVX group.

Improvements in vascular reactivity have been reported to occur in other vascular beds during tamoxifen therapy undertaken for the purpose of promoting effects similar to those of estrogen replacement in OVX rats. Such studies demonstrated that tamoxifen attenuates the vasoconstrictor response observed in estrogen deficiency $(35,36)$. Treatment with tamoxifen also normalizes the contractile response mediated by phenylephrine in isolated cerebral arteries of OVX animals (24).

The action of tamoxifen in producing vasodilatation in isolated vascular beds may be related to the ability of tamoxifen to inhibit protein kinase $C$ (37). Other studies have demonstrated that tamoxifen reduces the mRNA expression of the $\alpha_{1}$ c subunit of the L-type $\mathrm{Ca}^{2+}$ channel in the absence of estrogen and augments the mRNA expression of voltage-dependent potassium channels $\left(\mathrm{K}_{\mathrm{v}}\right)$, thus possibly contributing to the vasodilatory response (38).

Our findings reflect the long-term actions of tamoxifen as used clinically. The therapeutic use of tamoxifen is currently prescribed for a period of five years (39). For this reason, we used a chronic treatment protocol of 12 weeks at a clinically relevant dosage of tamoxifen. In the absence of estrogen, tamoxifen reduced MAP, interfered with exacerbated contractile responses and improved the vasodilatory responses of coronary vascular beds in the isolated hearts of hypertensive rats.

Finally, our results show that tamoxifen was capable of attenuating the exacerbated vasoconstrictor response to acetylcholine observed after ovariectomy in the OVX+TAMOX group and increasing the vasodilatory response to adenosine. Tamoxifen also reduced, but did not normalize, MAP in the OVX+TAMOX group, suggesting potentially beneficial effects of tamoxifen that may contribute to protection against cardiovascular disease, especially after menopause.

In this study, we demonstrated improvement in vascular coronary reactivity with tamoxifen treatment that may result in a reduced incidence of ischemic heart disease and coronary artery disease, especially in hypertensive states.

\section{Acknowledgments}

Research supported by grants and a fellowship from FACITEC (Vitória, Brazil) and CNPq. 


\section{References}

1. Coylewright M, Reckelhoff JF, Ouyang P. Menopause and hypertension: an age-old debate. Hypertension 2008; 51: 952-959.

2. Yang XP, Reckelhoff JF. Estrogen, hormonal replacement therapy and cardiovascular disease. Curr Opin Nephrol Hypertens 2011; 20: 133-138.

3. Wuest JH Jr, Dry TJ, Edwards JE. The degree of coronary atherosclerosis in bilaterally oophorectomized women. Circulation 1953; 7: 801-809.

4. Manson JE, Hsia J, Johnson KC, Rossouw JE, Assaf AR, Lasser NL, et al. Estrogen plus progestin and the risk of coronary heart disease. N Engl J Med 2003; 349: 523-534.

5. Hulley S, Grady D, Bush T, Furberg C, Herrington D, Riggs $B$, et al. Randomized trial of estrogen plus progestin for secondary prevention of coronary heart disease in postmenopausal women. Heart and Estrogen/Progestin Replacement Study (HERS) Research Group. JAMA 1998; 280: 605-613.

6. Moriarty $\mathrm{K}, \mathrm{Kim} \mathrm{KH}$, Bender JR. Minireview: estrogen receptor-mediated rapid signaling. Endocrinology 2006; 147: 5557-5563.

7. Li L, Hisamoto K, Kim KH, Haynes MP, Bauer PM, Sanjay A, et al. Variant estrogen receptor-c-Src molecular interdependence and $\mathrm{c}-\mathrm{Src}$ structural requirements for endothelial NO synthase activation. Proc Natl Acad Sci U S A 2007; 104: 16468-16473.

8. Prakash YS, Togaibayeva AA, Kannan MS, Miller VM, Fitzpatrick LA, Sieck GC. Estrogen increases $\mathrm{Ca}^{2+}$ efflux from female porcine coronary arterial smooth muscle. $A m \mathrm{~J}$ Physiol 1999; 276: H926-H934.

9. Grainger DJ, Weissberg PL, Metcalfe JC. Tamoxifen decreases the rate of proliferation of rat vascular smoothmuscle cells in culture by inducing production of transforming growth factor beta. Biochem J 1993; 294: 109-112.

10. Ludmer PL, Selwyn AP, Shook TL, Wayne RR, Mudge GH, Alexander RW, et al. Paradoxical vasoconstriction induced by acetylcholine in atherosclerotic coronary arteries. $N$ Engl J Med 1986; 315: 1046-1051.

11. Miller VM, Li L, Sieck GC. Endothelium-dependent effects of estrogen on vasomotor tone. Consequences of nongenomic actions. Vascul Pharmacol 2002; 38: 109-113.

12. White RE, Darkow DJ, Lang JL. Estrogen relaxes coronary arteries by opening BKCa channels through a cGMPdependent mechanism. Circ Res 1995; 77: 936-942.

13. Burger HG. Selective oestrogen receptor modulators. Horm Res 2000; 53 (Suppl 3): 25-29.

14. Couldwell WT, Weiss MH, DeGiorgio CM, Weiner LP, Hinton DR, Ehresmann GR, et al. Clinical and radiographic response in a minority of patients with recurrent malignant gliomas treated with high-dose tamoxifen. Neurosurgery 1993; 32: 485-489.

15. Buzdar A, Howell A, Cuzick J, Wale C, Distler W, HoctinBoes G, et al. Comprehensive side-effect profile of anastrozole and tamoxifen as adjuvant treatment for early-stage breast cancer: long-term safety analysis of the ATAC trial. Lancet Oncol 2006; 7: 633-643.

16. Love RR, Wiebe DA, Newcomb PA, Cameron L, Leventhal $\mathrm{H}$, Jordan VC, et al. Effects of tamoxifen on cardiovascular risk factors in postmenopausal women. Ann Intern Med
1991; 115: 860-864

17. Ek RO, Yildiz Y, Cecen S, Yenisey C, Kavak T. Effects of tamoxifen on myocardial ischemia-reperfusion injury model in ovariectomized rats. Mol Cell Biochem 2008; 308: 227235.

18. Potts JT, McKeown KP, Shoukas AA. Reduction in arterial compliance alters carotid baroreflex control of cardiac output in a model of hypertension. Am J Physiol 1998; 274: H1121H1131.

19. van Gorp AW, Schenau DS, Hoeks AP, Boudier HA, de Mey JG, Reneman RS. In spontaneously hypertensive rats alterations in aortic wall properties precede development of hypertension. Am J Physiol Heart Circ Physiol 2000; 278: $\mathrm{H} 1241-\mathrm{H} 1247$.

20. Doring HJ. The isolated perfused heart according to Langendorff technique - function - application. Physiol Bohemoslov 1990; 39: 481-504.

21. Figtree GA, Webb CM, Collins $P$. Tamoxifen acutely relaxes coronary arteries by an endothelium-, nitric oxide-, and estrogen receptor-dependent mechanism. J Pharmacol Exp Ther 2000; 295: 519-523.

22. Dubey RK, Oparil S, Imthurn B, Jackson EK. Sex hormones and hypertension. Cardiovasc Res 2002; 53: 688-708.

23. Thorin E, Pham-Dang M, Clement R, Mercier I, Calderone A. Hyper-reactivity of cerebral arteries from ovariectomized rats: therapeutic benefit of tamoxifen. Br J Pharmacol 2003; 140: 1187-1192.

24. Simon T, Boutouyrie P, Simon JM, Laloux B, Tournigand C, Tropeano Al, et al. Influence of tamoxifen on carotid intimamedia thickness in postmenopausal women. Circulation 2002; 106: 2925-2929.

25. Dickhout JG, Lee RM. Blood pressure and heart rate development in young spontaneously hypertensive rats. $\mathrm{Am} \mathrm{J}$ Physiol 1998; 274: H794-H800.

26. O'Malley CA, Hautamaki RD, Kelley M, Meyer EM. Effects of ovariectomy and estradiol benzoate on high affinity choline uptake, ACh synthesis, and release from rat cerebral cortical synaptosomes. Brain Res 1987; 403: 389-392.

27. Liu CC, Kuo TB, Yang CC. Effects of estrogen on genderrelated autonomic differences in humans. Am J Physiol Heart Circ Physiol 2003; 285: H2188-H2193.

28. Du XJ, Riemersma RA, Dart AM. Cardiovascular protection by oestrogen is partly mediated through modulation of autonomic nervous function. Cardiovasc Res 1995; 30: 161-165.

29. Skrzypiec-Spring M, Grotthus B, Szelag A, Schulz R. Isolated heart perfusion according to Langendorff-still viable in the new millennium. J Pharmacol Toxicol Methods 2007; 55: 113-126.

30. Moyses MR, Barker LA, Cabral AM. Sex hormone modulation of serotonin-induced coronary vasodilation in isolated heart. Braz J Med Biol Res 2001; 34: 949-958.

31. Santos RL, Abreu GR, Bissoli NS, Moyses MR. Endothelial mediators of 17 beta-estradiol-induced coronary vasodilation in the isolated rat heart. Braz J Med Biol Res 2004; 37 : 569-575.

32. Luscher TF, Boulanger CM, Dohi Y, Yang ZH. Endotheliumderived contracting factors. Hypertension 1992; 19: 117130. 
33. Jensen EV, Suzuki T, Numata M, Smith S, DeSombre ER. Estrogen-binding substances of target tissues. Steroids 1969; 13: 417-427.

34. Nirmala PB, Thampan RV. Ubiquitination of the rat uterine estrogen receptor: dependence on estradiol. Biochem Biophys Res Commun 1995; 213: 24-31.

35. Hutchison SJ, Chou TM, Chatterjee K, Sudhir K. Tamoxifen is an acute, estrogen-like, coronary vasodilator of porcine coronary arteries in vitro. J Cardiovasc Pharmacol 2001; 38: 657-665.

36. Tsang SY, Yao X, Chan HY, Chan FL, Leung CS, Yung LM, et al. Tamoxifen and estrogen attenuate enhanced vascular reactivity induced by estrogen deficiency in rat carotid arteries. Biochem Pharmacol 2007; 73: 1330-1339.

37. Wickman G, Vollrath B. Effects of tamoxifen on oxyhemoglobin-induced cerebral vasoconstriction. Eur J Pharmacol 2000; 390: 181-184.

38. Tsang SY, Yao X, Chan FL, Wong CM, Chen ZY, Laher I, et al. Estrogen and tamoxifen modulate cerebrovascular tone in ovariectomized female rats. Hypertension 2004; 44: 7882.

39. Controle do câncer de mama: documento do Consenso. http://www.inca.gov.br/publicacoes/Consensointegra.pdf. Accessed August 1, 2010. 